\title{
Assessing and Modelling the Influence of Household Characteristics on Per Capita Water Consumption
}

\author{
Wa'el A. Hussien ${ }^{1}$ - Fayyaz A. Memon ${ }^{1} \cdot$ \\ Dragan A. Savic ${ }^{1}$
}

Received: 22 January 2016 / Accepted: 30 March 2016 /

Published online: 26 April 2016

(C) The Author(s) 2016. This article is published with open access at Springerlink.com

\begin{abstract}
Sustainable urban water supply management requires, ideally, accurate evidence based estimations on per capita consumption and a good understanding of the factors influencing the consumption. The information can then be used to achieve improved water demand forecasts. Water consumption patterns in the developed countries have been extensively investigated. However, very little is known for the developing world. This paper investigates per capita water consumption resulting from water use activities in different types of households typically found in urban areas of the developing world. A data collection programme was executed for 407 households to extract information on household characteristics, water user behaviour and intensity and the nature of indoor and outdoor water use activities. The rigorous statistical analysis of the data shows that per capita water consumption increases with income: 241, 272 and 290 1/capita/day for low, medium and high income households, respectively. Additionally, the results suggest that per capita consumption increases with the number of adult female members in the household and almost one-third of consumption is via taps. The collected data has been used to develop statistical models using two different regression techniques: multiple linear (STEPWISE) and evolutionary polynomial regression (EPR). The inclusion of demographic parameters in the developed models considerably improved the prediction accuracy. Two of the best performing models are used to forecast the water demand for the city, using four future scenarios: market forces, fortress world, policy reform and great transition. The results suggest that the domestic water demand would be highest in the fortress world scenario due to the increase in population and size of built-up area.
\end{abstract}

Wa'el A. Hussien

wahh201@exeter.ac.uk

1 Centre for Water Systems, College of Engineering, Mathematics and Physical Sciences, University of Exeter, Exeter, Devon EX4 4QF, UK 
Keywords Water end-use $\cdot$ Household characteristics · Built-up area $\cdot$ Income $\cdot$ Evolutionary polynomial regression $\cdot$ STEPWISE regression

\section{Introduction}

Water scarcity is a major issue in many developed and developing countries. Rapid population growth, urbanization and climate change related uncertainties are some of the factors influencing land use patterns and need to be considered during water resources management planning. Since 2007, the fraction of urban population has exceeded the rural fraction and is largely attributed to the economic migration (United Nation 2015). In order to accommodate this rapid increase in urban population on limited urban land, there is a considerable upward shift towards developing apartments in multi-storey buildings with the associated change in physical household characteristics (e.g., built-up area, number of rooms and area of front garden). These characteristics can in turn influence domestic water consumption. Additionally, the interactions between climate change and land use and management can affect the availability of freshwater resources (Houghton-Carr et al. 2013), as a result of change in the amount of returned evapotranspiration to the atmosphere and also runoff and groundwater pathways (Holman and Hess 2014). Emphasis is growing on the implementation of demand management measures, water reuse and better understanding of our water consumption behaviours and factors influencing or contributing to domestic water consumption.

The modelling of domestic water demand has been effectively examined and analysed in the developed countries, while less effort has been made for the developing countries (Nauges and Whittington 2009). This can be due to the household's access to more than one type of water sources in the developing countries. Rizaiza (1991) developed water demand models for households supplied by water distribution network and tankers, separately, to estimate water demand in four cities in Saudi Arabia. Also, Cheesman et al. (2008) separated water demand for households with a private connection only and households combining private connection and well water. Different household characteristics are used for water demand modelling and estimation in the developing countries, such as, walking time to water source (Persson 2002), number of women in the household ( $\mathrm{Mu}$ et al. 1990), family size (Larson et al. 2006), education level (Madanat and Humplick 1993), income (Nauges and Strand 2007) and reliability of water from other sources (Nauges and van den Berg 2009). However, physical household characteristics (e.g. built-up area, garden area, number of rooms and number of floors) should be taken into account to develop effective models for domestic water demand estimation.

The domestic water consumption in Iraq is investigated in some studies. For example, Al-Samawi and Hassan (1988) and Isehak (2001) investigated the residential water demand in Basrah and Baghdad city, respectively. Al-Anbari et al. (2009) analysed the residential water consumption for Hilla city, and found that the number of occupants and hand wash basin taps have a significant impact on the household water consumption.

This paper examines water consumption for over 400 households, of different types, and explores the influence of various household characteristics on per capita consumption patterns currently prevailing in urban areas of an Iraqi city, Duhok. The collected water consumption data has been used to develop statistical models demonstrating the influence of household characteristics on the total per capita daily water consumption. A selection of statistical models 
is used to investigate the impact of four future scenarios (i.e., market forces, fortress world, policy reform and great transition) on likely changes in per capita consumption.

\section{Methodology for Data Collection}

Study Area Domestic water consumption patterns have been investigated for Duhok city, which is located in north-western Iraqi Kurdistan (Fig. 1). The city has a population of around 295,000 inhabitants with 42000 households and spreads over $577 \mathrm{~km}^{2}$, accounting for $0.13 \%$ of total area of Iraq (Kurdistan Regional Statistics Office 2014). The city witnessed a rapid expansion in the area covered and the growth in the population during several decades. This is due to the high fertility $(5 \%)$ and the movement from rural areas to the city (Kurdistan Ministry of Planning 2014).

One of the water sources in the city is Duhok earth dam with storage capacity of 47.5 million $\mathrm{m}^{3}$. The dam is mainly used for agricultural purposes (Kurdistan Ministry of Water Resources 2014). Domestic water $\left(66.1 \times 10^{6} \mathrm{~m}^{3} /\right.$ year $)$ is supplied by the national water supply board through a pipe from Khrabdeem, the main water treatment plant in Duhok. In addition, around $8.3 \times 10^{6} \mathrm{~m}^{3} /$ year of water from up to 100 wells is pumped for domestic use (Duhok Directorate of Water and Sewerage 2014). Water is supplied to households 3 to 4 times every week with each supply session lasting not more than $6 \mathrm{~h}$. People store water in overhead tanks and consume it for different activities including drinking.

Data Collection Programme A detailed questionnaire was prepared in the native language (Kurdish) and included over 40 questions. A multiple-choice format was used to answer some of the questions. Household characteristics, such as number of children, elders, adult males and females, household type, total built-up area, garden area, number of rooms, number of floors and monthly income were investigated. Furthermore, questions regarding the frequency, duration of use and flow rate of each water end-use (e.g. showering, hand wash basin, toilet flushing, dishwashing, laundry, house washing, cooking, garden watering and vehicle washing) were also included.

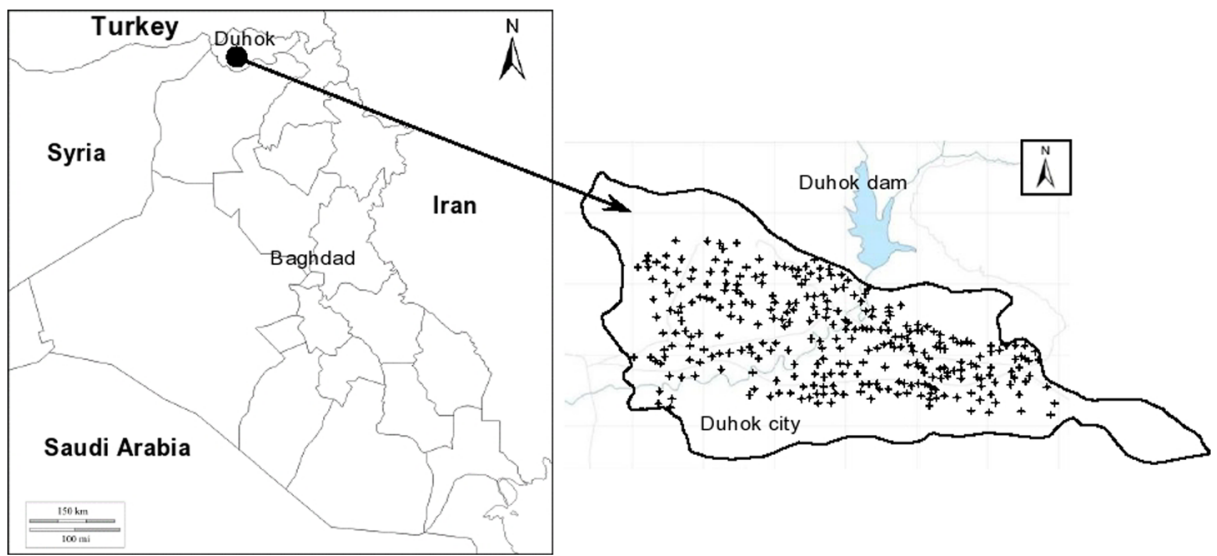

Fig. 1 Duhok city location in Kurdistan, Iraq and the distribution of surveyed households in the city (Kurdistan Ministry of Planning 2014) 
The questionnaire was distributed to 419 randomly selected households in February 2015. The replies were received from 407 households. The analyses of the collected data was performed using IBM SPSS Statistics (v. 22) package and included estimation of statistical parameters (i.e., average, minimum, maximum and distribution shape identification through kurtosis and skewness) for the characteristics of the 407 households. Based on per capita income, the dwellings were divided into low, medium and high income groups and each group was analyzed separately to identify the influence of variation in income on household and water use characteristics. A summary of results is discussed in Section 3.

Development of Statistical Models The research resulted in a comprehensive data set on factors contributing to water consumption. Using the data set, 24 statistical models were developed using two techniques: multiple linear regression (STEPWISE) and evolutionary polynomial regression (EPR). The resulting models and their performance is discussed in Section 3.4 .

\section{Results and Discussion}

\subsection{Household Characteristics}

The analyses of household characteristics of 407 residential units $(92 \%$ houses and $8 \%$ apartments) are summarized in Table 1. It shows that the average household occupancy is 7.04 persons, which is approximately equivalent to the average standard family size (6.7 persons) in Duhok as reported by KRSO (2014). In terms of family composition, the average number of adult females, adult males and children are 2.33, 2.27 and 2.22, respectively. The average number of elders ( $\geq 65$ years) was very low (0.22), accounting only for $3.2 \%$ of the investigated sample.

The socio-economic characteristics of the households show that the average built-up area of all floors is between 100 and $500 \mathrm{~m}^{2}$ with approximately $30 \mathrm{~m}^{2}$ occupied by the garden. Of the 407 households, $58 \%$ were single-story, $36 \%$ were double-story and $6 \%$ were triple-story. The average number of rooms was just over 4 . The variation in the family income was high and ranged from $3 \times 10^{5}$ Iraqi Dinar $(\mathrm{ID}) /$ month $(\approx £ 150)$ to $44.7 \times 10^{5} \mathrm{ID} /$ month $(\approx £ 2,200)$ with average per capita income equivalent to $25 \times 10^{4} \mathrm{ID} /$ month $(\approx £ 125)$.

\subsubsection{The Influence of Household Characteristics on the Total Average Water Consumption (l/hh/day)}

The correlation coefficient can be used to assess the strength of relationship between variables (Kerns 2010). The analyses of the data suggest a strong positive relationship between household occupancy (i.e., the number of people in the household) and total water consumption $(\mathrm{R}=0.87)$ whilst there is a negative relationship between per person usage and household occupancy. Water consumption increases with the increase in the total household built-up area, number of rooms and garden area with a correlation coefficient of $0.94,0.96$ and 0.77 , respectively (Fig. 2). This finding is consistent with those of Cavanagh et al. (2002) who found that the household built-up area and number of rooms increased water consumption in the developed countries (e.g. the U.S. and Canada). 


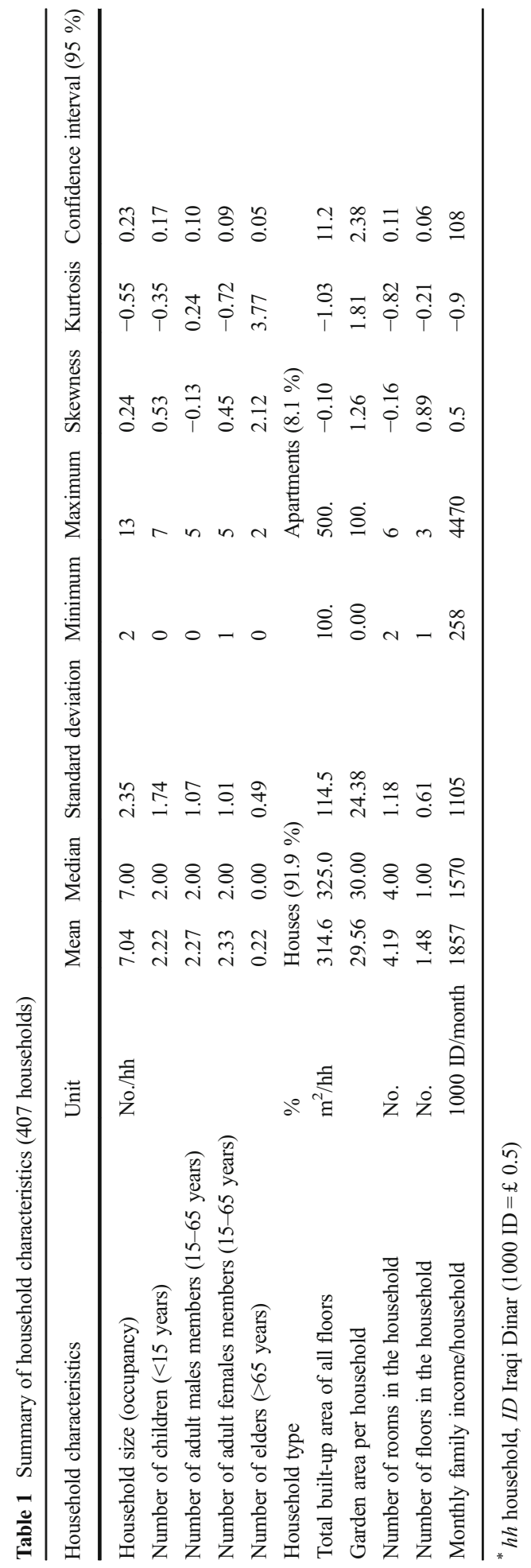



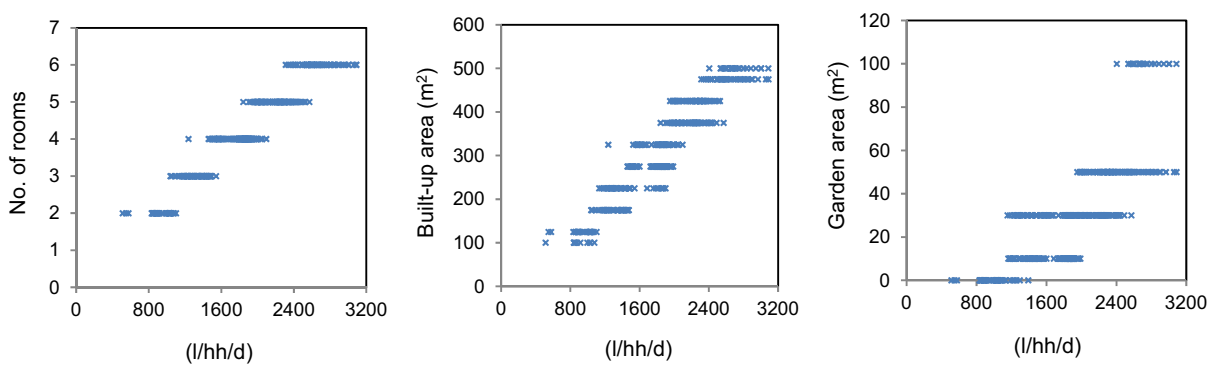

Fig. 2 Relationship between household water consumption $(1 / \mathrm{hh} / \mathrm{d})$ and household characteristics

\subsubsection{The Influence of Household Characteristics on the Average Per Capita Water Consumption $(l / p / d)$}

The distribution of the average daily per capita water consumption for the whole sample is shown in Fig. 3, suggesting that the average is about $271 \mathrm{l} / \mathrm{p} / \mathrm{d}$. For houses it is approximately $274 \mathrm{l} / \mathrm{p} / \mathrm{d}$ and that for apartments is about $247 \mathrm{l} / \mathrm{p} / \mathrm{d}$. The higher consumption for houses is mainly because of additional outdoor water use. In agreement with Edwards and Martin (1995), the daily per capita consumption increases with increase in the total built-up area of the household; however, it decreases with the increase in the number of household occupants. The decline in per person usage suggests household uses of water such as clothes washing, dish washing and water used for cooking and cleaning are more efficient on a per person basis for higher occupancy households. The influence of children is higher than elders. In other words, increased number of children in the household leads to a higher reduction in per capita consumption than elders. On the other hand, increased number of male adults in the household reduces per capita consumption and the increase in female members increases per capita consumption. This increase in per capita consumption with the increase in number of females in a household appears to be because of the fact that many female members most of times stay at home and have primary responsibility to look after family.

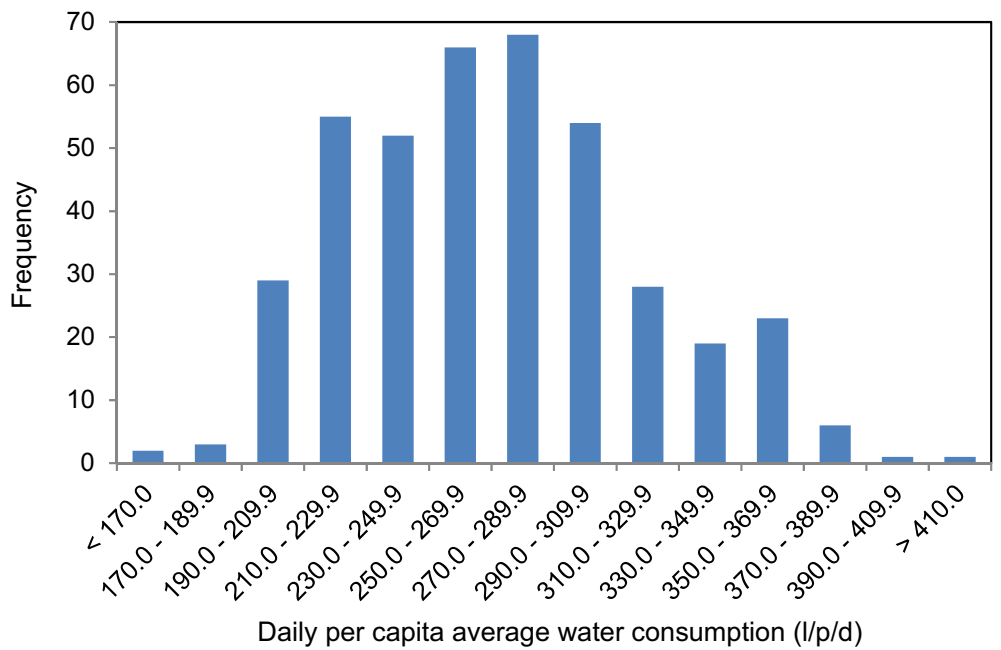

Fig. 3 Frequency distribution of average per capita water consumption (1/p/d) 


\subsubsection{Influence of Per Capita Income on the Average Per Capita Water Consumption $(l / p / d)$}

In Iraq, a household socio-economic survey was conducted by the Central Statistical Organization (CSO) and KRSO in 2012. In the survey, the monthly family income was divided into three groups (Table 2). This classification was based on the average family size of 6.7 persons. The last column in Table 2 shows per capita income for respective household groups and has been obtained by dividing the household income by the average family size. Using per capita figures of column three, the investigated 407 households where divided into three income groups (Table 3).

The analysis of the data shows that the average per capita consumption increases with the household income (i.e., 241, 272 and 290 1/p/d in low, medium and high income group, respectively). Although the average per capita water consumption rises with the increase in the household income, the fraction of water used for different activities broadly remains the same in all the investigated households regardless of the income group (Fig. 4). The figure shows that the highest fraction of water consumption is via taps. This is in contrast to many countries in the developed world where about one-third of water is used to flush toilets (Post 2000).

\subsection{Average Per Capita Water Use for Different End-Uses (Micro-Components)}

A household's total water consumption is disaggregated into a number of end-uses: showering, bath, hand wash basin, toilet flushing, dishwashing, laundry, cooking, house washing, garden watering, car washing and swimming pool. The average daily use of each of these components in all income groups is illustrated in Fig. 5. A notable feature in this figure is the considerable variation in daily water end-use per person between income groups. It is apparent from this figure that the swimming pool use in all income groups is low (less than $0.2 \mathrm{l} / \mathrm{p} / \mathrm{d}$ ). Of the 407 households, only two houses were found to have a swimming pool and, therefore, they will not be included in any further analysis. Another finding is the per capita water consumption for outdoor purposes (garden watering, car washing and swimming pool) is less than $10 \%$ of the total daily usage in all income groups. However, the consumption for outdoor purposes may become much higher in the summer season.

\subsection{The Influence of Per Capita Income on Water End-Uses}

The summary of average values of water end-use parameters per person (e.g., frequency, duration of use and flow rate) is illustrated in Table 4. It shows the comparison between these

Table 2 Income groups classification for Iraq (CSO and KRSO 2012)

\begin{tabular}{lll}
\hline Income group & \multicolumn{2}{l}{ Income range in Iraqi Dinar (ID) } \\
\cline { 2 - 3 } & Per household & Per capita \\
\hline Low & $<1 \times 10^{6}$ & $<15 \times 10^{4}$ \\
Medium & $1 \times 10^{6}-2 \times 10^{6}$ & $15 \times 10^{4}-30 \times 10^{4}$ \\
High & $>2 \times 10^{6}$ & $>30 \times 10^{4}$ \\
\hline
\end{tabular}


Table 3 Number of investigated households in different income groups

\begin{tabular}{llll}
\hline Income group & Low & Medium & High \\
\hline Number of households & 92 & 176 & 139 \\
\hline
\end{tabular}

parameters in low, medium and high income households. The key findings are explained in the following sections.

\subsubsection{Shower and Bath}

Shower and bath use are positively related to family income (Gato 2006). Throughout the study of 407 households, there were no baths recorded in low and medium income families. There were only 10 baths recorded in high income households with a very low frequency (once a week) of use.

The daily per capita water use for showering is the function of the frequency, the duration and the flow rate of shower. Although, the frequency of showering is high ( 0.61 showers $/ \mathrm{p} / \mathrm{d})$ in the high income group, the flow rate of shower $(8.39 \mathrm{l} / \mathrm{min})$ is lower than that recorded in the low and medium income groups (Table 4). Most of the high income households were found to be constructed recently and therefore they are likely to have more water efficient appliances (e.g., shower heads). The duration of shower was found to be less sensitive to income groups. However, frequency of showering tends to increase with increase in per capita income.

\subsubsection{Hand Wash Basin (taps)}

In all income groups, hand wash basin uses are the highest water users accounting for approximately $32 \%$ of the total water use (Fig. 4). Similarly to showering, hand wash basin water consumption is influenced by the number of times the basin is used.

As with showers, the flow rate from hand wash basin taps decreases with the increase in household income. This confirms that the high income group households are relatively new
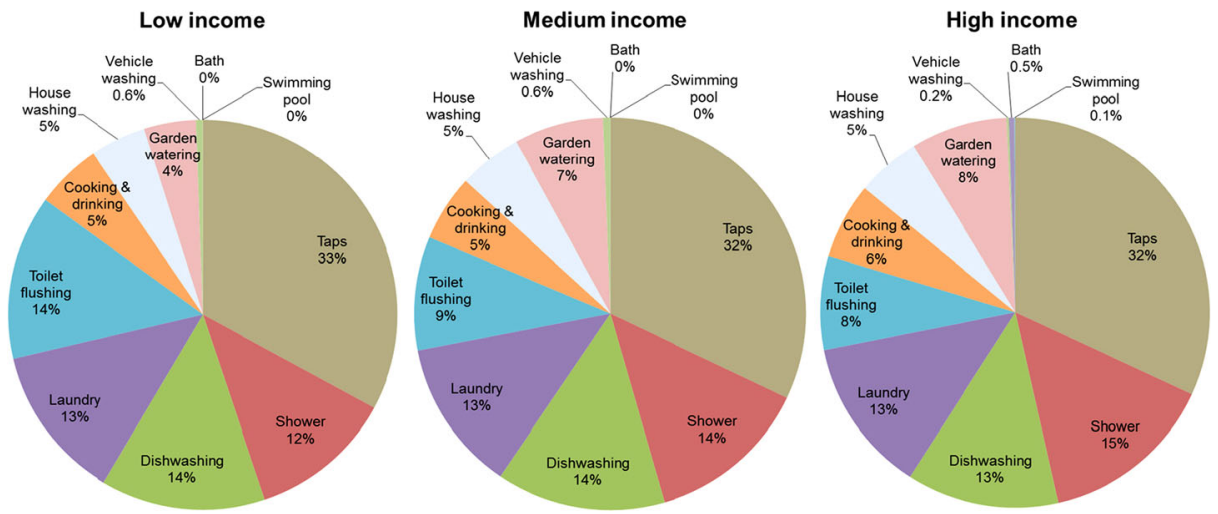

Fig. 4 Summary of percentages of water end-uses in all income groups 


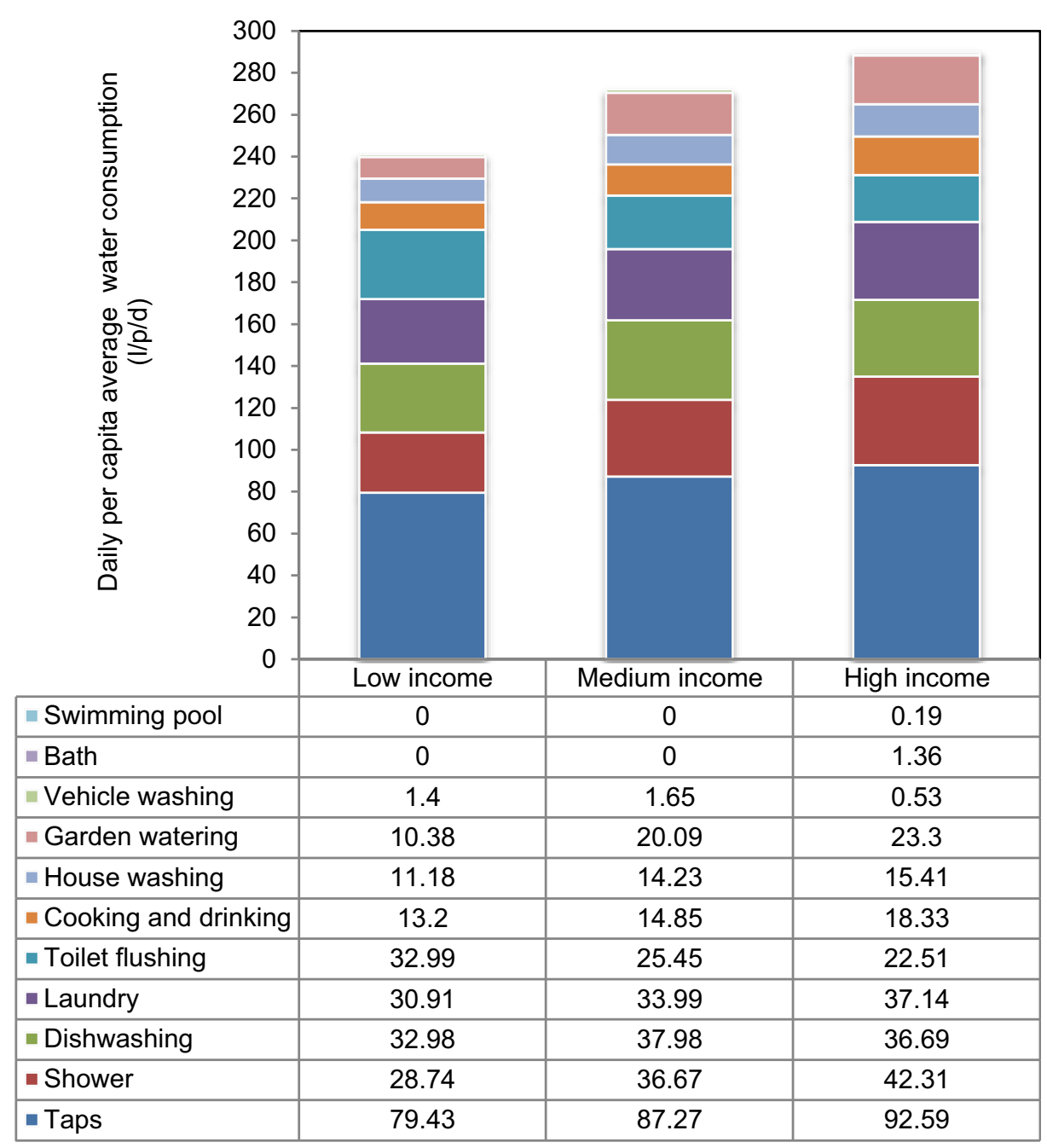

Fig. 5 Impact of per capita monthly income on water end-uses in Duhok

and fitted with water efficient appliances which decrease the flow rate. The frequency of hand wash basin use rises with the increase in income. The duration of use is similar in low, medium and high income families. The duration of tap use for all income groups is about $60 \mathrm{~s}$ per event. When multiplied with the frequency of hand wash basin tap use, the total daily per capita tap duration becomes 9.68, 10.49 and $11.38 \mathrm{~min} /$ capita/day for low, medium and high income households, respectively. The duration of the daily hand wash basin tap use obtained in this study is much higher than the values found in the literature of developed countries. It ranges between 6.66 and $8.33 \mathrm{~min} /$ capita/day in Yarra valley, Australia (Roberts 2005) and much lower than this (i.e., $2.73 \mathrm{~min} /$ capita/day) in the Netherlands (Gato 2006). The high tap duration can be attributed to additional water using activities in the Islamic culture (e.g., ablution before each prayer time). 


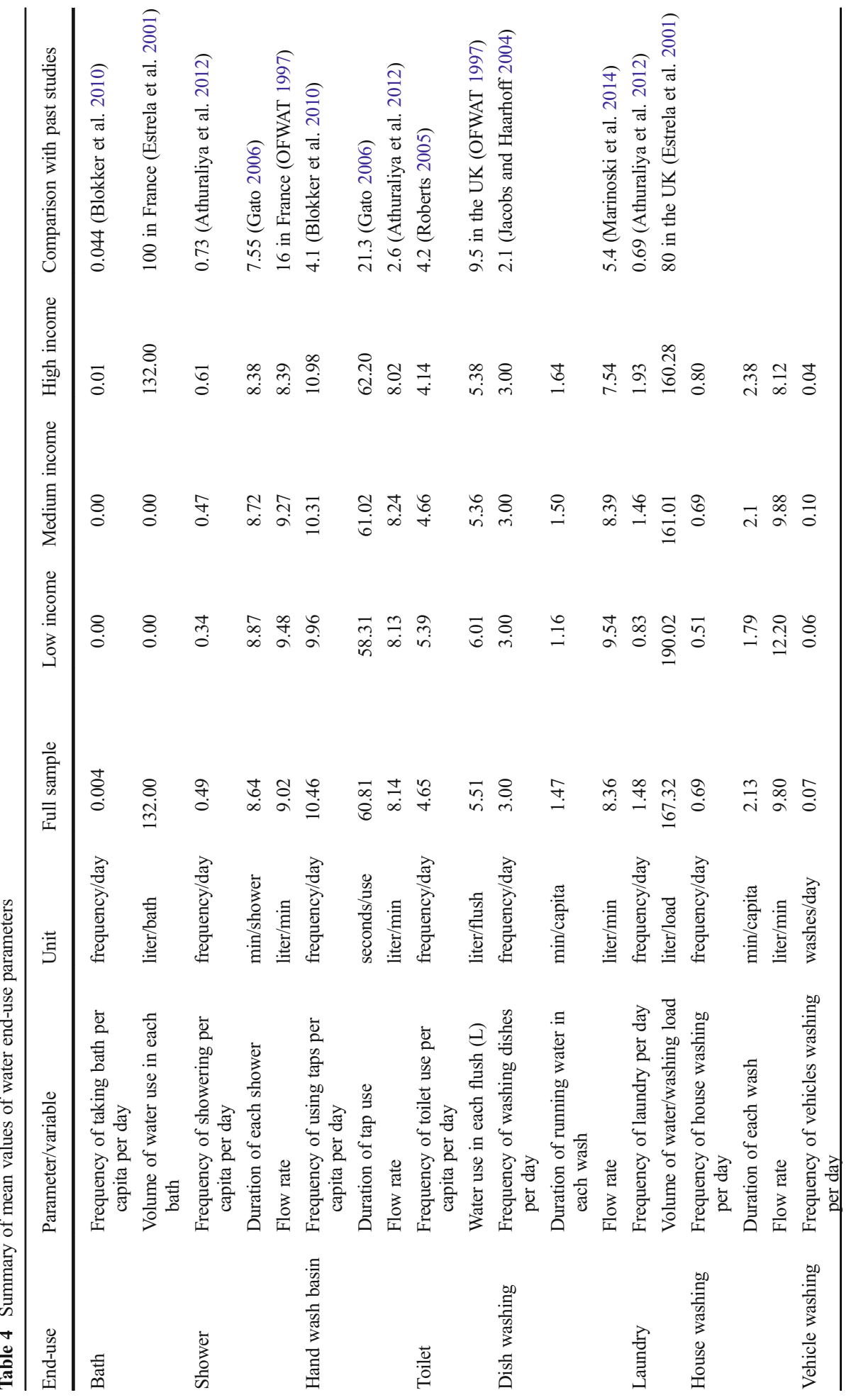




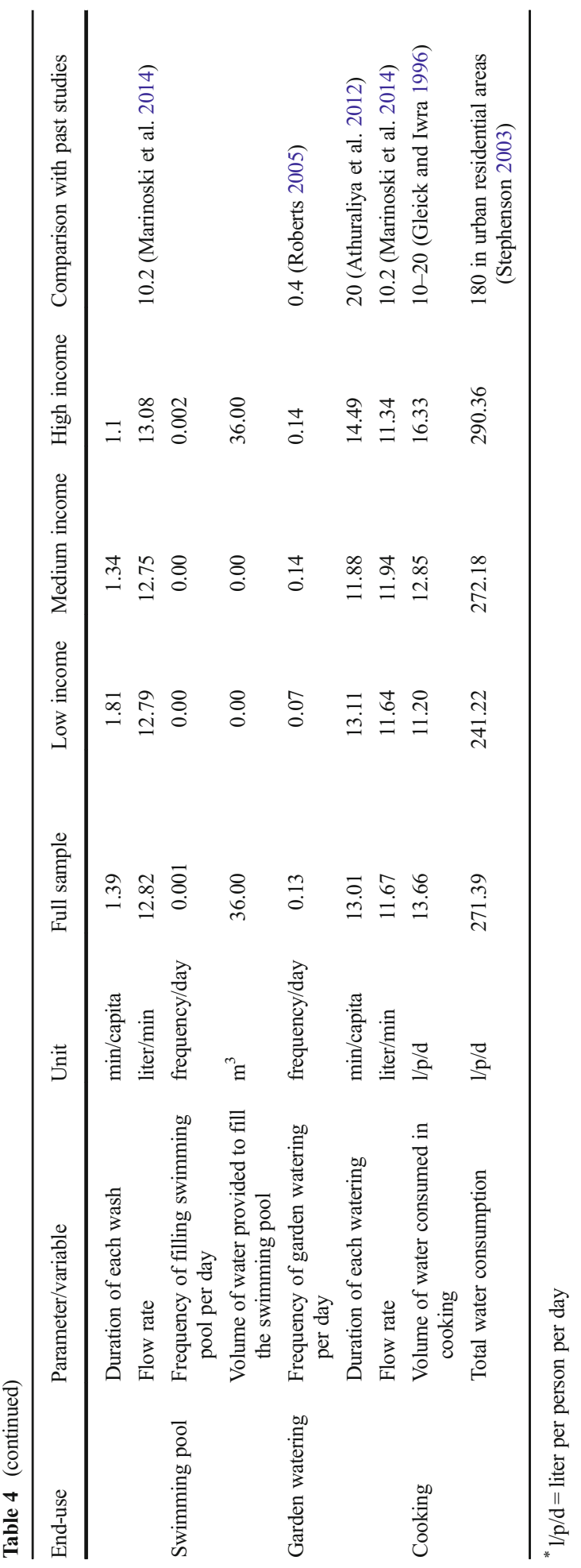




\subsubsection{Toilet Use}

In line with the observation made above, again high income group households appear to have water efficient toilet (5.4 1/flush) in comparison to low income households (6.0 1/flush). This increases the average daily per capita toilet consumption in low income group to $33.0 \mathrm{l} / \mathrm{p} / \mathrm{d}$, it being higher than that in medium $(25.5 \mathrm{l} / \mathrm{p} / \mathrm{d})$ and high $(22.5 \mathrm{l} / \mathrm{p} / \mathrm{d})$ income families.

The frequency of toilet per capita daily use was higher in low income families (5.4 times/ day) than that in medium (4.7 times/day) and high (4.1 times/day) income families. From the data presented in Table 4, it appears that in the medium and high income households water consumption for personal hygiene related activities is higher. This is reflected in higher frequencies of shower, clothes-wash and hand wash basin use indicating an increased emphasis on cleanliness. The less emphasis (inability) on cleanliness in low income group may be a cause of increased water borne diseases; consequently the frequency of toilet use might increase. Another reason for lower toilet use frequency for high income group is the high number of people in employment working away from home during the day.

\subsubsection{Dishwashing}

Dishwashing accounted for the second highest end-use being approximately $14 \%$ of total water use in all income groups (Fig. 4). Although, $7 \%$ of the 407 households own dishwasher, they still wash dishes manually. The daily water consumption for dishwashing is a function of flow rate, duration and number of washes. The frequency of washing dishes is same in all income groups, i.e., after each meal (breakfast, lunch and dinner). The flow rate of kitchen tap decreases with the increase in household income from $9.5 \mathrm{l} / \mathrm{min}$ in low income to $7.5 \mathrm{l} / \mathrm{min}$ in high income households (Table 4). However, the variability in total water use for dishwashing between income groups is due to the duration of each dishwashing session, which is dependent on the number of dishes and indirectly the size of the family. For example, the duration of each wash in six occupants family for each income group was found to be 6.3, 9.3 and $10.5 \mathrm{~min}$ for low, medium and high income group, respectively.

\subsubsection{Laundry}

The main parameters to identify water consumption for laundry washing are the volume of water used per washing cycle and the frequency. The volume of water used in each wash is fixed depending upon the brand, style, and size of the washing machine in each house. The analysis shows that there is a difference in the average volume of water used per wash between income groups, accounting approximately for 160 1/washing load in medium and high income houses and much higher in low income (190 1/washing load) (Table 4). It looks that in comparison with lower income group; medium and higher income households have water efficient washing machines.

The second parameter (the frequency of laundry per household per week) can be influenced by the number of occupants. The collected data suggests that it rises with the increase in household income, indicating more emphasis on hygiene with increased income. Therefore, the difference in total amount of laundry water consumption is significantly high between income groups. It is 146, 235 and 310 liters/hh/day in low, medium and high income families, respectively. 


\subsubsection{House Washing}

About $5 \%$ of the total water consumption is used for house washing (Fig. 4). The house washing activities include floor washing, washroom and kitchen cleaning. The analysis shows that the frequency and duration of household washing increase with the rise in the household income. The frequency is 3.6, 4.8 and 5.6 times/week with duration of each wash approximately $8.4,14.2$ and $19.5 \mathrm{~min}$ in low, medium and high income households, respectively. This suggests that the emphasis on cleanliness and hygiene increases with the increase in the household income or due to the size of household area.

\subsubsection{Cooking}

According to the studies of the NRC (1989) and Black (1990), food preparations in both developed and developing countries would require about 10 to $20 \mathrm{l} / \mathrm{p} / \mathrm{d}$ of water; for example, in Sri Lanka, daily per capita average water consumption for cooking is $16 \mathrm{l} / \mathrm{p} / \mathrm{d}$ (Sivakumaran and Aramaki 2010). The Duhok study shows that average value for water required for food preparation lies within the values found in the literature. However, water consumption for food preparation increases with the increase in the family income, accounting 11.2, 12.9 and $16.3 \mathrm{l} /$ $\mathrm{p} / \mathrm{d}$ in low, medium and high income households, respectively (Table 4).

\subsubsection{Garden Watering}

Outdoor water use (garden watering, car washing and swimming pool) is related to the size of the residential dwelling area (Gato 2006). In terms of the frequency of garden watering, it is much lower in low income group than that in the medium and high income groups (Table 4). Most of the houses recorded only one irrigation event per week. This may be because of the timing of the study, which was conducted during winter time. In order to quantify the seasonality impact, a similar study in the same area will be repeated to account for water consumption variations in the summer.

The duration of each watering session in the high income group is the longest (approximately $2 \mathrm{~h}$ ). This appears to be mainly because of the larger garden area (average of $51.8 \mathrm{~m}^{2}$ ) in comparison with low $\left(9.3 \mathrm{~m}^{2}\right)$ and medium $\left(22.6 \mathrm{~m}^{2}\right)$ income households. However, the flow rate from the outside tap for the garden watering is broadly similar $(11.5 \mathrm{l} / \mathrm{min})$ in all households regardless of their income group (Table 4). Therefore, the total volume of water used for garden irrigation in high income households is clearly the highest (192 liters/hh/day) with less consumption in medium (134 liters/hh/day) and low (59 liters/hh/day) income houses.

\subsubsection{Vehicle Washing}

In terms of water use for vehicle washing, the highest consumer is medium income families (75.6 1/hh/week), which is probably because of less ownership in low income families (47.2 1/ $\mathrm{hh} /$ week). On the other hand, people in high income households prefer their cars washed at washing services rather than doing it themselves $(28 \mathrm{l} / \mathrm{hh} /$ week $)$. Because of this, water consumption for vehicle washing in high income group is low. It can be seen from the data in Fig. 5 that the average per capita water use for vehicle washing is relatively small in all income groups but this may increase in the summer season due to the frequent dust storms. 


\subsection{Modelled Daily Per Capita Usage with Household Characteristics}

The water consumption data from the 407 households was divided into calibration and validation sets. $70 \%$ of the data was used for calibration (i.e., training), while the remaining $30 \%$ was spared for validation (i.e., testing) purposes. The calibration data set was used to develop statistical models to predict per capita consumption as a function of household characteristics. The household characteristics were divided into two groups, that is:

- Demographic characteristics: number of children, elders, adult males and adult females.

- Physical characteristics: total household built-up area, garden area, number of rooms, number of floors and per capita income.

Two different techniques were used to build regression models in order to identify the models which are computationally efficient and provide reliable predictions. The two techniques applied are: multiple linear regression (STEPWISE) and evolutionary polynomial regression (EPR). These techniques have been used for modelling the water related applications (Mountains 2013; Doglioni et al. 2010) and achieved good results.

\subsubsection{Models Based on Multiple Linear Regression (STEPWISE)}

Multiple linear regression technique has been used widely to explore the relationship between the dependent and several independent variables (Abdul-Wahab et al. 2005). The technique is looking for the combination of relevant independent variables to construct the best fit model based on strong statistical foundations. One of the multiple regression techniques is STEPWISE, which is a potential approach for selecting the best combination of independent variables (Cevik 2007).

The STEPWISE multiple regression approach is applied using IBM SPSS Statistics (v. 22) software to determine the best subset model for daily per capita water use estimation. Using the calibration set of data, the relationships between the independent variables (household characteristics) and the dependent variable (per capita water consumption) were investigated and the values of correlation coefficient (R) are shown in Table 5. From the table, it can be seen

Table 5 Correlation coefficients between household characteristics and per capita water consumption

\begin{tabular}{|c|c|c|c|c|c|c|c|c|c|c|}
\hline & & \multicolumn{9}{|c|}{ Correlation coefficient value (R) } \\
\hline & & \multicolumn{4}{|c|}{ Demographic characteristics } & \multicolumn{5}{|c|}{ Physical characteristics } \\
\hline & & $\begin{array}{l}\text { No. of } \\
\text { children }\end{array}$ & $\begin{array}{l}\text { No. of } \\
\text { adult } \\
\text { females }\end{array}$ & $\begin{array}{l}\text { No. of } \\
\text { adult } \\
\text { males }\end{array}$ & $\begin{array}{l}\text { No. of } \\
\text { elders }\end{array}$ & $\begin{array}{l}\text { No. of } \\
\text { rooms }\end{array}$ & $\begin{array}{l}\text { No. of } \\
\text { floors }\end{array}$ & $\begin{array}{l}\text { Total } \\
\text { built-up } \\
\text { area }\end{array}$ & $\begin{array}{l}\text { Garden } \\
\text { area }\end{array}$ & Income \\
\hline \multirow{4}{*}{$\begin{array}{l}\text { Per capita water } \\
\text { consumption } \\
(1 / \mathrm{p} / \mathrm{d})\end{array}$} & $\begin{array}{l}\text { All investigated } \\
\text { households }\end{array}$ & -0.560 & 0.467 & -0.474 & -0.204 & -0.028 & -0.064 & 0.008 & 0.013 & 0.602 \\
\hline & $\begin{array}{l}\text { Low income } \\
\text { households }\end{array}$ & -0.745 & -0.279 & -0.263 & -0.408 & -0.773 & 0.000 & -0.664 & -0.361 & 0.777 \\
\hline & $\begin{array}{l}\text { Medium income } \\
\text { households }\end{array}$ & -0.808 & 0.467 & -0.766 & -0.270 & -0.859 & -0.638 & -0.699 & -0.330 & 0.844 \\
\hline & $\begin{array}{l}\text { High income } \\
\text { households }\end{array}$ & -0.501 & 0.196 & -0.807 & -0.254 & -0.766 & -0.532 & -0.678 & -0.443 & 0.803 \\
\hline
\end{tabular}

${ }^{*} 1 / \mathrm{p} / \mathrm{d}=$ litres per capita per day 
that the strongest relationship of per capita consumption is with the number of children in the household and per capita income. The selection or deletion of an independent variable for the regression model is based on the strength of relationship (i.e., the magnitude of the correlation coefficient) and also its contribution to the decrease of the residual sum of squares (Cevik 2007). The regression coefficients and model are then statistically tested at the every iteration to select or delete the independent variable. The statistical testes are:

- The ANOVA (F-test) to examine the significance of the regression model. The model is statically significant when $p<0.05$, which means the overall regression model is a good fit for the independent variables entered in the model (Yasar et al. 2012).

- The $t$-test to examine the significance of the regression coefficients. The regression coefficients are statistically significant (i.e. different to zero) if $p<0.05$ (Yasar et al. 2012).

Using STEPWISE approach with the calibration set of data of whole investigated households, three models were developed based on demographic, physical and whole characteristics (i.e., Model 1, 2 and 3 in Table 6, respectively). The similar procedure is repeated using the calibration set of low, medium and high income households data. These models are shown in Table 6 and they are statistically significant $(p<0.05)$.

The predictions from these models were plotted against the actual per capita water consumption values obtained from the study as shown in Fig. 6 . The figure shows that the trend-lines of validation and calibration set are relatively identical in all cases. Additionally, the $\mathrm{R}^{2}$ value improves further when the water consumption data was disaggregated into low, medium and high income groups.

\subsubsection{Models Based on Evolutionary Polynomial Regression (EPR)}

The evolutionary polynomial regression (EPR) is a modelling technique which combines the effectiveness of genetic algorithm with numerical regression to develop mathematical model expressions (Giustolisi and Savic 2009). This technique has been used in a number of other applications, such as evapotranspiration process (El-Baroudy et al. 2010), rainfall-groundwater dynamics (Doglioni et al. 2010), water distribution and wastewater networks (Berardi et al. 2008), and have shown good performance.

The EPR MOGA-XL tool ${ }^{1}$ (ver.1), which performs multi-objective genetic algorithm search for plausible models, is used to develop the models for daily per capita water use estimation. The two objective functions that were used for the evolutionary search by EPR are:

- The minimization of the number of terms, and

- Maximization of the accuracy of the model to calibration set (i.e. minimization of the summation of square errors) (Giustolisi and Savic 2009).

Various mathematical nonlinear expressions were chosen to model per capita water consumption as a function of household characteristics (i.e., independent variables). However, the results of simple mathematical structure (Equation 1) were the best in most cases. For each mathematical model, the candidate exponents for the independent variables (ES) and the maximum number of terms are selected through experimentation. The bias term is considered as zero. Finally, the number of generations within genetic algorithm is selected as 400 .

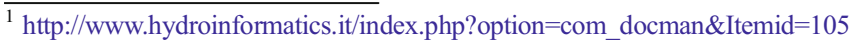




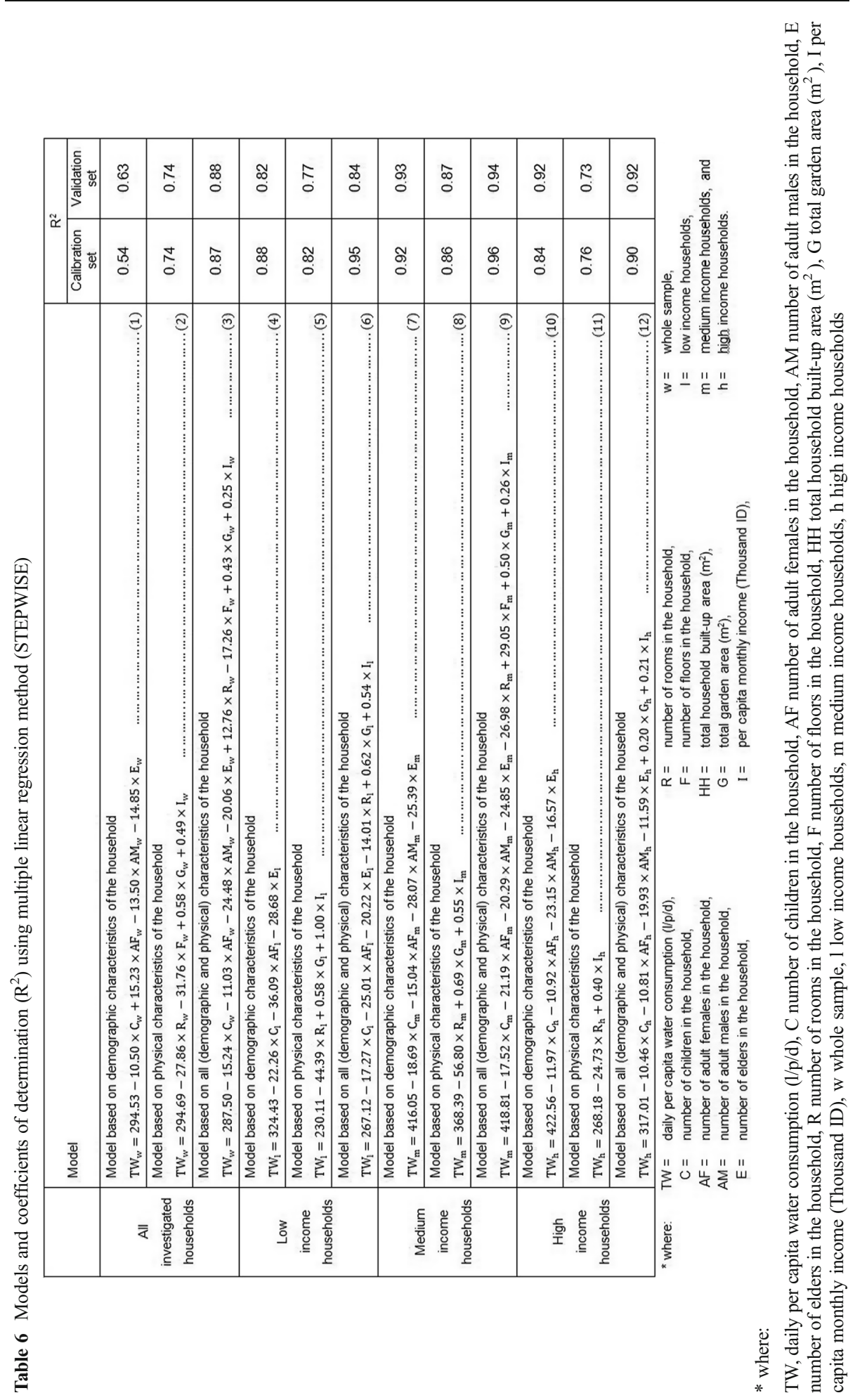




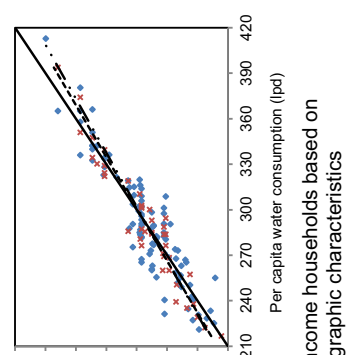

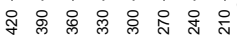
pə|॥әроW (pd)

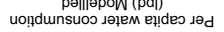

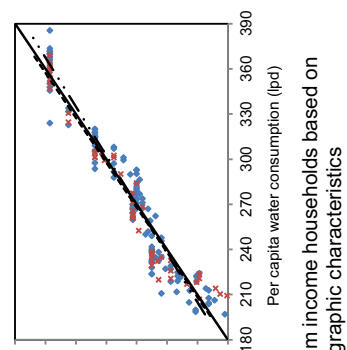

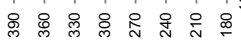
pə|ाәроW (pd))

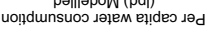

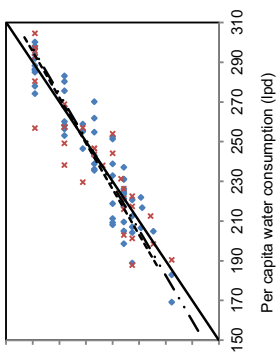

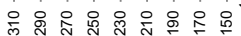
pə|॥әроW (pd)

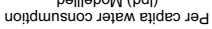

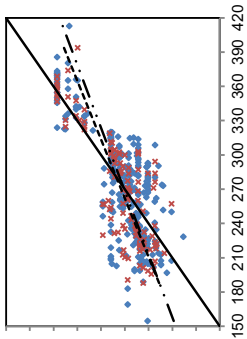

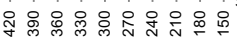

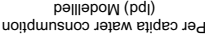

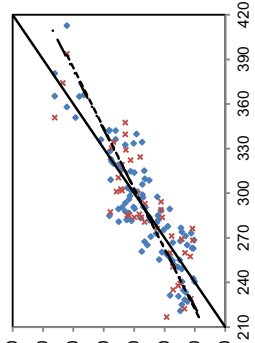

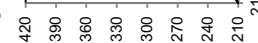

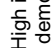

pə||әроw (pd)
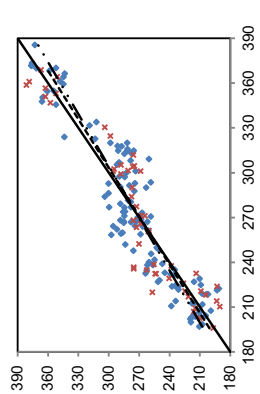

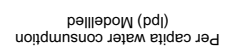

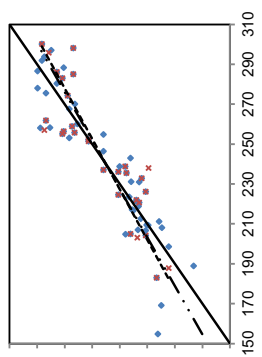

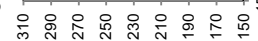
pe|l||pow ( $p d \mid)$

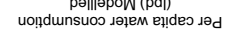

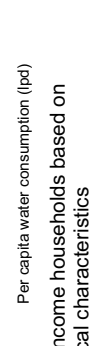

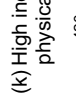
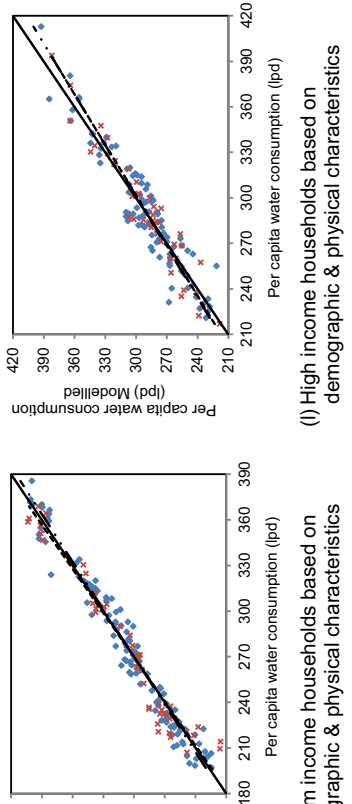

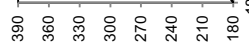
pə||әроW (pd!)
uo!̣dunsuos גәңем eł!deo dәd
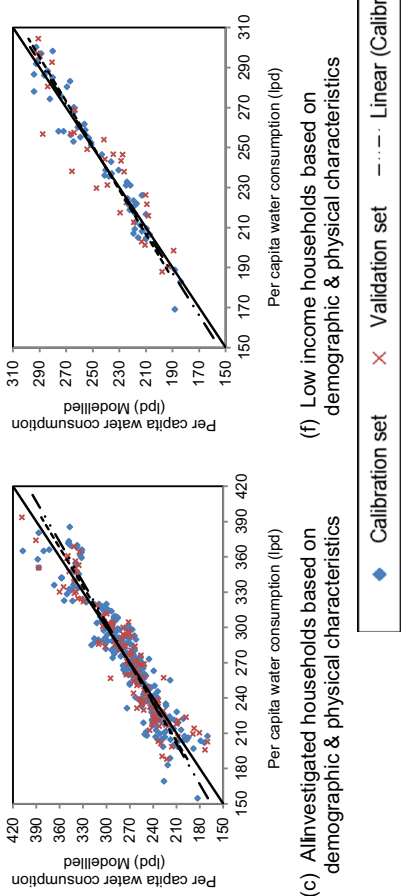


$$
Y=a_{0}+\sum_{j=1}^{m} a_{j} \times f\left\{\left(X_{1}\right)^{E S(j, 1)} \ldots \ldots\left(X_{k}\right)^{E S(j, k)}\right\}
$$

where,

$Y \quad$ the EPR estimated water consumption

$a_{\mathrm{o}}$ the bias term

$m \quad$ the total number of polynomial terms

$a_{j} \quad$ the coefficients of $j_{t h}$ polynomial term

$f(X)$ the polynomial function constructed by EPR

$E S \quad$ the matrix of unknown exponents, and

$X_{k} \quad$ the $k_{\mathrm{t} h}$ independent variable (household characteristics)

Using the calibration set of data ( $70 \%$ of the whole investigated households) with the EPR MOGA-XL tool, three nonlinear regression models are developed as a function of demographic, physical and all characteristics (Model 1, 2 and 3 in Table 7, respectively). Similarly, three mathematical models were developed for each income group (low, medium and high) using their calibration set of data as shown in Table 7. These models have been chosen due to achieving the highest coefficient of determination $\left(\mathrm{R}^{2}\right)$.

The predictions from EPR models were plotted against the actual per capita water consumption values as shown in Fig. 7. For all models in this figure, the trend-lines of calibration and validation set of data are relatively identical. From this figure, it can be concluded that the $\mathrm{R}^{2}$ value increases when the models were developed for each household income group. Moreover, the $\mathrm{R}^{2}$ value increases significantly when all (demographic and physical) household characteristics were included in the model rather than only demographic or physical characteristics.

\subsubsection{Comparison of Models}

The twelve models developed in EPR and STEPWISE were compared using $\mathrm{R}^{2}$ values as shown in Table 8 . From the table it can be seen that the $\mathrm{R}^{2}$ values of both modelling techniques are relatively high (over 0.8 ) for most cases. However, the $\mathrm{R}^{2}$ of EPR based model improved considerably when the number of polynomial terms and the exponents was increased. On the other hand, STEPWISE based model also offers good predictions.

Both modelling approaches suggest the strong influence of demographic characteristics on per capita water consumption when the data was disaggregated into household income groups and the role of household physical characteristics is minimal.

\subsubsection{Sensitivity}

Sensitivity measures to what extent the magnitude of a dependent variable (i.e. estimated total water demand) could change over the practical range of variation of the input independent variables (e.g., household characteristics) (Jacobs 2004). Sensitivity analysis provides insights into the applicability of the model under consideration. Additionally, it identifies the effect of each household characteristic on the estimated water demand.

Jacobs (2004) considered the range of variation of each input parameter (i.e. household characteristic) as the standard deviation below and above the average. The sensitivity for each input parameter is tested using three values (i.e., average, average + standard deviation and 


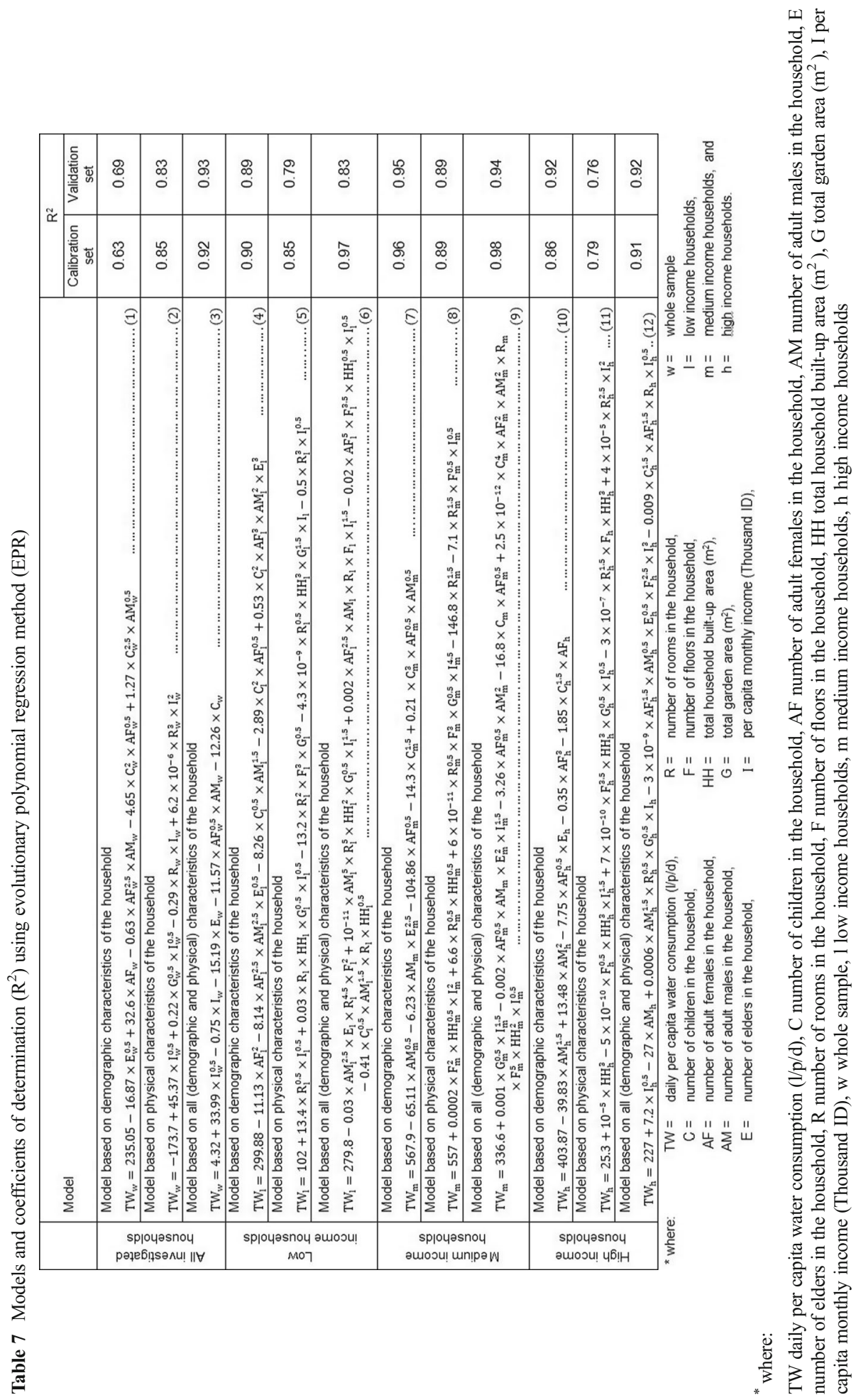




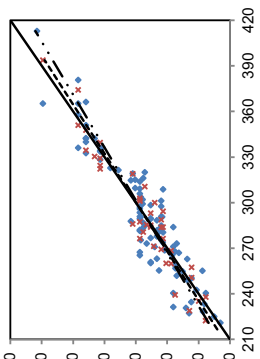

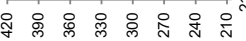
pə|ाәроW (pd)

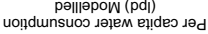

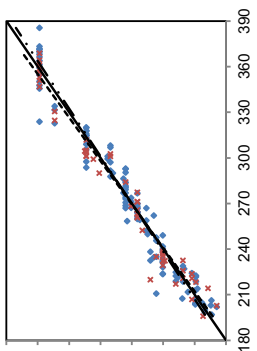

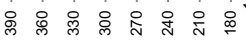

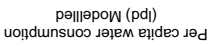

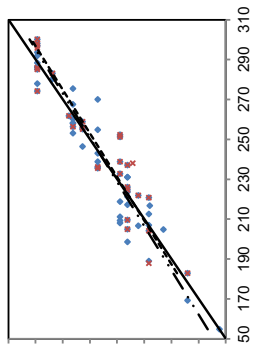

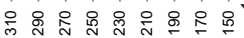

pə||әроW (pd))

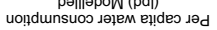

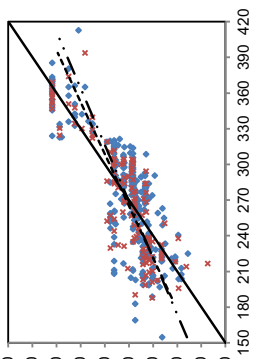

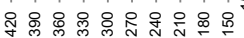

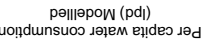

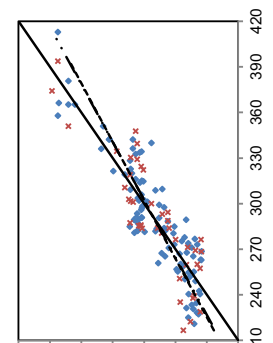

多家 pә|ाәроw (pd)

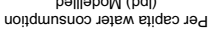
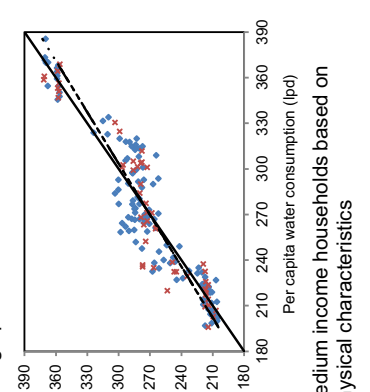
pə|ाәроW (pd) pə||әроW (pd!)
uo!̣dunsuos sәңем еұ!deo sәd
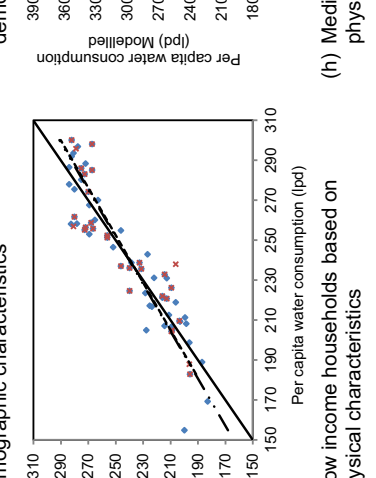

잉

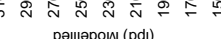

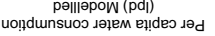

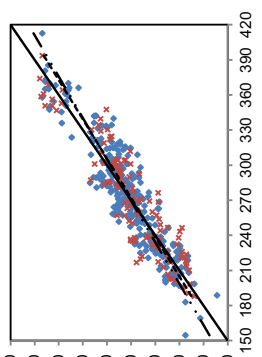

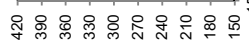

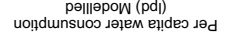
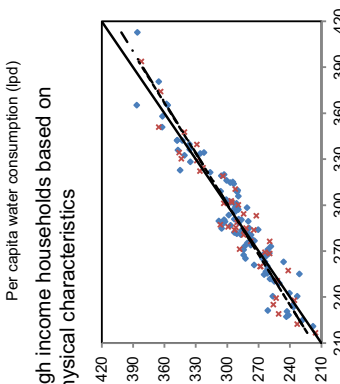

홀

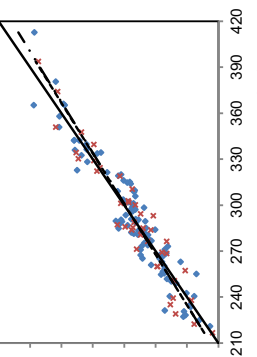

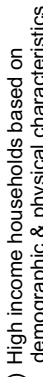
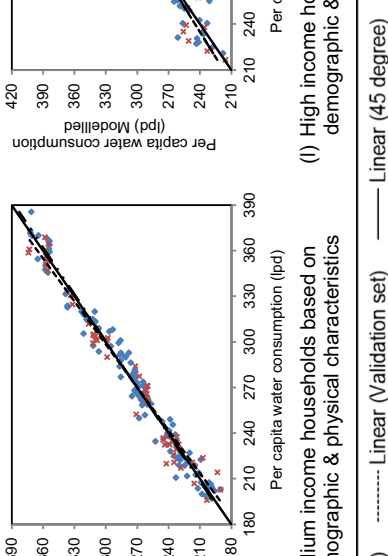

일
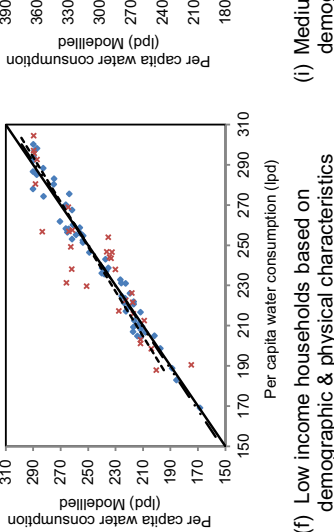
Table 8 Coefficients of determination $\left(\mathrm{R}^{2}\right)$ of the final regression models

\begin{tabular}{|c|c|c|c|c|c|c|}
\hline & \multicolumn{2}{|c|}{$\begin{array}{l}\text { Per capita water } \\
\text { consumption modelled } \\
\text { with household } \\
\text { demographic } \\
\text { characteristics }\end{array}$} & \multicolumn{2}{|c|}{$\begin{array}{l}\text { Per capita water } \\
\text { consumption modelled } \\
\text { with household physical } \\
\text { characteristics }\end{array}$} & \multicolumn{2}{|c|}{$\begin{array}{l}\text { Per capita water } \\
\text { consumption modelled } \\
\text { with demographic and } \\
\text { physical characteristics }\end{array}$} \\
\hline & STEPWISE & EPR & STEPWISE & EPR & STEPWISE & EPR \\
\hline All investigated households & 0.54 & 0.63 & 0.74 & 0.85 & 0.87 & 0.92 \\
\hline Low income households & 0.88 & 0.90 & 0.82 & 0.85 & 0.95 & 0.97 \\
\hline Medium income households & 0.92 & 0.96 & 0.86 & 0.89 & 0.96 & 0.98 \\
\hline High income households & 0.84 & 0.86 & 0.76 & 0.79 & 0.90 & 0.91 \\
\hline
\end{tabular}

average - standard deviation). The low and high value of each household characteristic are calculated using the average and standard deviation statistics in Table 1. The calculated upper and lower value of each household characteristic have been used with STEPWISE and EPR developed models to estimate the annual total water demand as shown in Fig. 8. The figure shows that the developed models are very sensitive to per capita income, number of children and number of adult males in the households.

\section{Model Application}

\subsection{Scenarios Definition}

In this paper, the implication of four alternative scenarios on the domestic water demand estimation is explored. These are market forces (MF), fortress world (FW), great transition

(a)

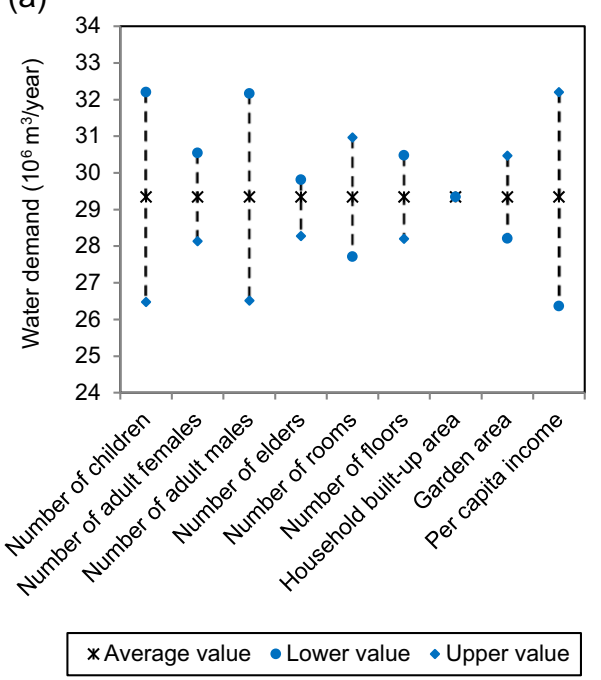

(b)

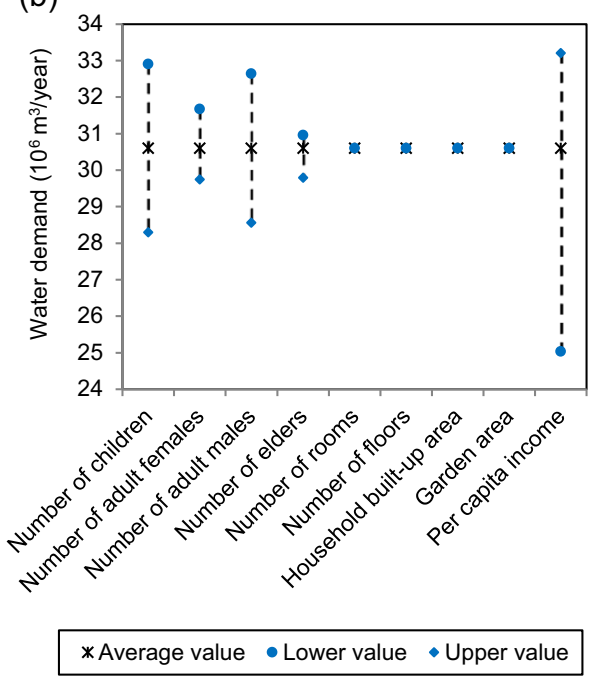

Fig. 8 Sensitivity analysis of input parameters for (a) STEPWISE and (b) EPR based domestic water demand prediction models for Duhok city 
(GT) and policy reform (PR). The definitions of these scenarios are given by Global Scenario Group (GSG) (Kemp-Benedict et al. 2002). These alternative pathways for world development have been extensively used in numerous global, regional, and national studies (Hunt et al. 2012). Each one of these scenarios tells a different plausible story of the twenty-first century with varying patterns of resource use, environmental impacts, and social conditions (Raskin et al. 2010).

\subsection{Implication of Future Scenarios on Water Demand}

The expected annual growth rate values of all indicators (i.e., population, income and built-up area) from the long-term trends analysis for each scenario relevant to the Middle East region are collected from Global Scenario Group (GSG 2002) as summarized in Table 9. Using average annual growth rate values of these indicators with STEPWISE and EPR developed models, annual demand has been simulated for 35 years ahead and is shown in Fig. 9. The time horizon of 35 years is the most often considered timeline in scenarios (Hunt et al. 2012; Ercin and Hoekstra 2014) and also recommended for socioeconomic planning (Simonovic and Fahmy 1999).

The figure shows that of the four considered scenarios, the total domestic water demand would be highest in the fortress world scenario. This is mainly because of relatively higher increase in population and built-up area in this scenario (Table 9).

\section{Conclusion}

This paper studied the domestic water consumption at end-use level in a developing country. The influence of household characteristics (demographic and socio-economic) on the water consumption was investigated. Using multiple linear regression (STEPWISE) and evolutionary polynomial regression (EPR) method, 24 statistical models were developed to estimate the daily per capita water consumption as a function of household characteristics. The developed models have been trained and validated. The STEPWISE and EPR regression models were compared. Finally, the best fit models were used to predict the future water demand for the city under the

Table 9 Growth rate of each indicator in GSG scenarios

\begin{tabular}{|c|c|c|c|c|}
\hline \multirow[t]{2}{*}{ GSG scenarios } & \multirow[t]{2}{*}{ Period } & \multicolumn{3}{|c|}{ Average annual growth rate of indicators $(\%)$} \\
\hline & & Population & Income & Built-up area \\
\hline \multirow[t]{2}{*}{ Market forces (KF) } & $1995-2025$ & 2.2 & 1.8 & 2.3 \\
\hline & $2025-2050$ & 1.1 & 1.6 & 1.5 \\
\hline \multirow[t]{2}{*}{ Fortress world (FW) } & 1995-2025 & 2.4 & 1.7 & 2.5 \\
\hline & $2025-2050$ & 1.5 & 0.7 & 1.7 \\
\hline \multirow[t]{2}{*}{ Great transition $(\mathrm{GT})$} & 1995-2025 & 2.0 & 2.3 & 1.8 \\
\hline & $2025-2050$ & 0.8 & 1.8 & 0.5 \\
\hline \multirow[t]{2}{*}{ Policy reform (PR) } & 1995-2025 & 2.1 & 1.9 & 2.0 \\
\hline & $2025-2050$ & 1 & 1.7 & 0.9 \\
\hline
\end{tabular}



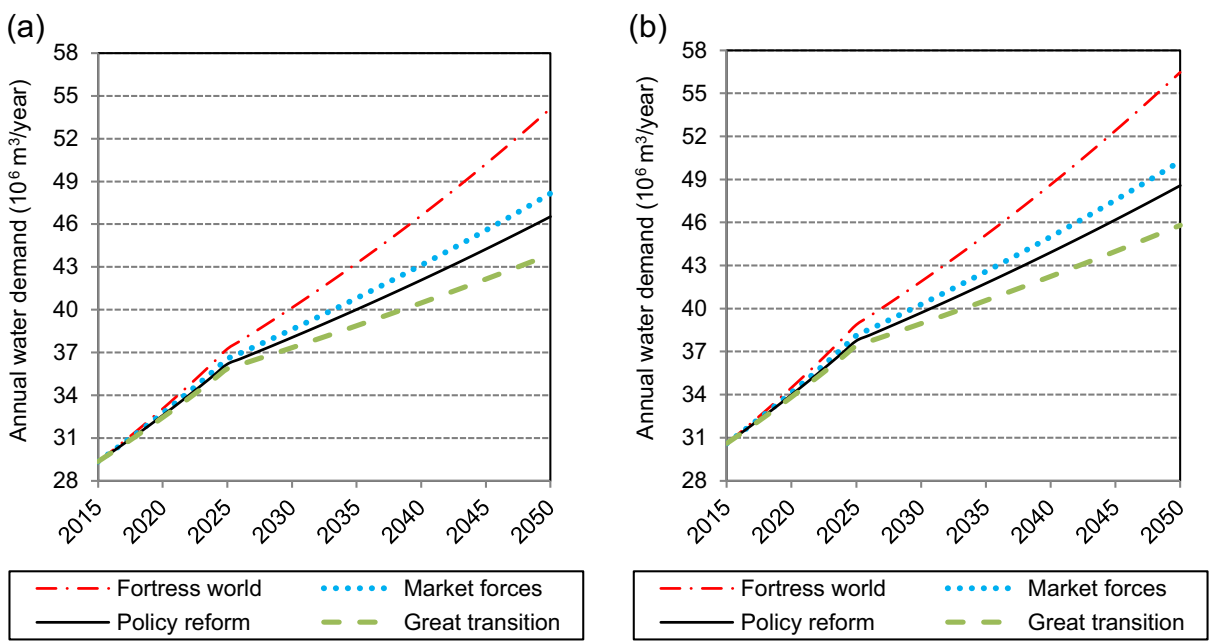

Fig. 9 Impact of four scenarios on total domestic water demand using (a) STEPWISE and (b) EPR

impact of four future scenarios. The key messages from the analysis of the presented work are:

- The per capita water consumption increases with the rise in household income and decreases with the increase in the household occupancy.

- Frequency of all water end-uses increases with the increase in per capita income except for toilet usage. Toilet use frequency in low income households is higher than that in medium and high income groups.

- The duration of hand wash basin tap in Duhok is much higher than typical values in the developed world. This indicates an additional water use activities (e.g. ablution) via the hand wash basin tap.

- Flow rate from different water end-uses decreases with increase in the per capita income, suggesting that households in high income group are relatively new and fitted with water efficient appliances.

- Per capita consumption decreases with the increase in male adults, elders and children but increases with the increase in number of adult females in a household. Additionally, the change in the number of elders and children has identical effect on per capita consumption.

- Using the collected data, it is possible to predict per capita water consumption. The quality of prediction improves when the full data was disaggregated into low, medium and high income group households.

- The models based on EPR offer a marginal improvement in the predictions quality.

- The demographic characteristics provide more accurate predictions of per capita water consumption than the predictions resulting from the use of physical characteristics of the investigated households.

- Of the investigated scenarios, domestic water demand is expected to be highest in the fortress world scenario. This is because of the expected growth rate of population and built-up area is high in this scenario. 
Open Access This article is distributed under the terms of the Creative Commons Attribution 4.0 International License (http://creativecommons.org/licenses/by/4.0/), which permits unrestricted use, distribution, and reproduction in any medium, provided you give appropriate credit to the original author(s) and the source, provide a link to the Creative Commons license, and indicate if changes were made.

\section{References}

Abdul-Wahab SA, Bakheit CS, Al-Alawi SM (2005) Principle component and multiple regression analysis in modeling of ground-level ozone and factors affecting its concentrations. Environ Model Softw 20(10):12631271

Al-Anbari RH, Al-Baidhani JH, Samaka IS (2009) Residential water demand analysis in Hilla city. Iraqi J Mech Mater Eng volume B:334-346

Al-Samawi AA, Hassan JS (1988) An analysis of residential demand for water: a case study of the city of Basrah. Arab Gulf J Sci Res A6(2):268-271

Athuraliya A, Roberts P, Brown A (2012) Residential water use study volume 2-Summer 2012. Yarra Valley Water, Melbourne

Berardi L, Kapelan Z, Giustolisi O, Savic D (2008) Development of pipe deterioration models for water distribution systems using EPR. J Hydroinf 10(2):113-126

Black M (1990) From hand pumps to health: the evolution of water and sanitation programmes in Bangladesh. United Nations Children's Fund, (UNICEF), India and Nigeria

Blokker JME, Vreeburg JGH, Van Dijk JC (2010) Simulating residential water demand with stochastic end-use model. J Water Resour Plan Manag 136(1):19-26

Cavanagh SM, Hanemann WM, Stavins RN (2002) Muffled price signals: Household water demand under increasing-block prices. FEEM Working Paper No. 40

Central Statistical Organisation (CSO) and Kurdistan Regional Statistics Office (KRSO) (2012) Iraqi household socio-economic survey report

Cevik A (2007) Unified formulation for web crippling strength of cold-formed steel sheeting using stepwise regression. J Constr Steel Res 63(10):1305-1316

Cheesman J, Bennett J, Son TVH (2008) Estimating household water demand using revealed and contingent behaviors: evidence from Viet Nam. Water Resour Res 44

Doglioni A, Mancarella D, Simeone V, Giustolisi O (2010) Inferring groundwater system dynamics from hydrological time-series data. Hydrol Sci J-J Sci Hydrol 55(4):593-608

Duhok Directorate of Water and Sewerage (2014)

Edwards K, Martin L (1995) A methodology for surveying domestic consumption. Water Environ J 9(5):477488

El-Baroudy I, Elshorbagy A, Carey SK, Giustolisi O, Savic D (2010) Comparison of three data-driven techniques in modelling the evapotranspiration process. J Hydroinf 12(4):365-379

Ercin EA, Hoekstra YA (2014) Water footprint scenarios for 2050: a global analysis. Environ Int 64:71-82

Estrela T, Menéndez M, Dimas M, Leonard J, Ovesen INB, Fehér NJ, Consult V (2001) Sustainable water use in Europe. Office for Official Publications of the European Communities

Gato S (2006) Forecasting urban residential water demand. PhD thesis, RMIT University

Giustolisi O, Savic DA (2009) Advances in data-driven analyses and modelling using EPR-MOGA. J Hydroinf 11(3):225-236

Gleick PH, Iwra M (1996) Basic water requirements for human activities: meeting basic needs. Water Int 21(2): 83-92

GSG (2002) Global scenario results. Global Scenarios Group, Tellus Institute, Boston, URL http://www.gsg.org/ gsgdata/scen_data_selector.cgi

Holman I P, Hess TM (2014) Development of a range of plausible future land use, land management and growing season changes

Houghton-Carr HA, Boorman DB, Heuser K (2013) Land use, climate change and water availability: Phase 2a. Rapid evidence assessment: results and synthesis

Hunt VDL, Lombardi DR, Atkinson S, Barber A, Barnes M, Boyko C, Brown J, Bryson J, Butler D, Caputo S, Caserio M, Coles R, Farmani R, Gaterell M J, Hale J, Hales C, Hewitt N, Jankovic L, Jefferson I, MacKenzie R, Memon F A, Pugh T, Rogers DC F, Smith D, Whyatt D, Weingaertner C (2012) Using scenarios to explore urban UK futures: a review of the literature 1997 to 2011. Working Document

Isehak RJ (2001) An analysis of residential demand for water: a case study of the city of Baghdad for the Period from 1995 to 1998. M.Sc. Thesis, University of Technology 
Jacobs HE (2004) A conceptual end-use model for residential water demand and return flow. $\mathrm{PhD}$ thesis, Rand Afrikaans University

Jacobs HE, Haarhoff J (2004) Structure and data requirements of an end-use model for residential water demand and return flow. Water SA 30(3):293-304

Kemp-Benedict E, Heaps C, Raskin P (2002) Global scenario group futures. Technical notes Stockholm, Stockholm Environment Institute, Global Scenario Group 464

Kerns GJ (2010) Introduction to probability and statistics using r. Lulu.com

Kurdistan Ministry of Planning (2014) URL Available at: http://www.mop.krg.org

Kurdistan Ministry of Water Resources (2014)

Kurdistan Regional Statistics Office (KRSO) (2014)

Larson B, Minten B, Razafindralambo R (2006) Unravelling the linkages between the millennium development goals for poverty, education, access to water and household water use in developing countries: evidence from Madagascar. J Dev Stud 42(1):22-40

Madanat S, Humplick F (1993) A model of household choice of water supply systems in developing countries. Water Resour Res 29(5):1353-1358

Marinoski A, Vieira A, Silva A, Ghisi E (2014) Water end-uses in low-income houses in Southern Brazil. Water 6(7):1985-1999

Mountains B (2013) Principal component regression analysis in water demand forecasting: an application to the Blue Mountains, NSW, Australia. J Hydrol Environ Res 1(1):49-59

Mu X, Whittington D, Briscoe J (1990) Modeling village water demand behavior: a discrete choice approach. Water Resour Res 26(4):521-529

National Research Council (NRC) (1989) Recommended dietary allowances. National Academies

Nauges C, Strand J (2007) Estimation of non-tap water demand in Central American cities. Resour Energy Econ 29(3):165-182

Nauges C, Van Den Berg C (2009) Perception of health risk and averting behavior: an analysis of household water consumption in Southwest Sri Lanka. Working Paper 08.09.253. LERNA, Toulouse

Nauges C, Whittington D (2009) Estimation of water demand in developing countries: an overview. World Bank Res Obs 25(2):263-294

OFWAT (1997) International comparison of the demand for water: a comparison of the demand for water in three European countries: England and Wales, France and Germany. WRc, UK

Parliamentary Office of Science and Technology (POST) (2000) Water efficiency in the home

Persson TH (2002) Household choice of drinking-water source in the Philippines. Asian Econ J 16(4):303-316

Raskin PD, Electris C, Rosen RA (2010) The century ahead: searching for sustainability. Sustainability 2(8): 2626-2651

Rizaiza O (1991) Residential water usage: a case study of the major cities of the western region of Saudi Arabia. Water Resour Res 27(5):667-671

Roberts P (2005) Yarra valley water: 2004 residential end-use measurement study. Yarra Valley Water, Melbourne

Simonovic SP, Fahmy H (1999) A new modelling approach for water resources policy analysis. Water Resour Res 35(1):295-304

Sivakumaran S, Aramaki T (2010) Estimation of household water end use in Trincomalee, Sri Lanka. Water Int 35(1):94-99

Stephenson D (2003) Water resources management. A. A. Balkema Publishers

United Nations (2015) World urbanization prospects. United Nations Publications. Department of Economic and Social Affairs, Population Division

Yasar A, Bilgili M, Simsek E (2012) Water demand forecasting based on stepwise multiple nonlinear regression analysis. Arab J Sci Eng 37(8):2333-2341 